\title{
Partnership for fragility bone fracture care provision and prevention program (P4Bones): study protocol for a secondary fracture prevention pragmatic controlled trial
}

Isabelle Gaboury ${ }^{1,2^{*}}$, Hélène Corriveau ${ }^{3,4}$, Gilles Boire ${ }^{2,5}$, François Cabana ${ }^{2,5}$, Marie-Claude Beaulieu', Pierre Dagenais ${ }^{6}$, Suzanne Gosselin ${ }^{1,7}$, Earl Bogoch ${ }^{8,9}$, Marie Rochette ${ }^{10}$, Johanne Filiatrault ${ }^{11,12}$, Sophie Laforest ${ }^{11,13,14}$, Sonia Jean ${ }^{15}$, Alvine Fansi, ${ }^{6,16}$, Diane Theriault ${ }^{17}$ and Bernard Burnand ${ }^{18}$

\begin{abstract}
Background: Fractures associated with bone fragility in older adults signal the potential for secondary fracture. Fragility fractures often precipitate further decline in health and loss of mobility, with high associated costs for patients, families, society and the healthcare system. Promptly initiating a coordinated, comprehensive pharmacological bone health and falls prevention program post-fracture may improve osteoporosis treatment compliance; and reduce rates of falls and secondary fractures, and associated morbidity, mortality and costs.

Methods/design: This pragmatic, controlled trial at 11 hospital sites in eight regions in Quebec, Canada, will recruit community-dwelling patients over age 50 who have sustained a fragility fracture to an intervention coordinated program or to standard care, according to the site. Site study coordinators will identify and recruit 1,596 participants for each study arm. Coordinators at intervention sites will facilitate continuity of care for bone health, and arrange fall prevention programs including physical exercise. The intervention teams include medical bone specialists, primary care physicians, pharmacists, nurses, rehabilitation clinicians, and community program organizers.

The primary outcome of this study is the incidence of secondary fragility fractures within an 18-month follow-up period. Secondary outcomes include initiation and compliance with bone health medication; time to first fall and number of clinically significant falls; fall-related hospitalization and mortality; physical activity; quality of life; fragility fracture-related costs; admission to a long term care facility; participants' perceptions of care integration,

expectations and satisfaction with the program; and participants' compliance with the fall prevention program. Finally, professionals at intervention sites will participate in focus groups to identify barriers and facilitating factors for the integrated fragility fracture prevention program.

This integrated program will facilitate knowledge translation and dissemination via the following: involvement of various collaborators during the development and set-up of the integrated program; distribution of pamphlets about osteoporosis and fall prevention strategies to primary care physicians in the intervention group and patients in the control group; participation in evaluation activities; and eventual dissemination of study results.
\end{abstract}

Study/trial registration: Clinical Trial.Gov NCT01745068

(Continued on next page)

\footnotetext{
*Correspondence: isabelle.gaboury@usherbrooke.ca

'Department of Family Medicine and Emergency Medicine, University of Sherbrooke, Sherbrooke, QC, Canada

${ }^{2}$ Centre de recherche clinique Étienne-Le Bel, Sherbrooke, QC, Canada

Full list of author information is available at the end of the article
} 


\section{Background}

Among Canadians over 50 years of age, close to two in five women and one in six men will experience at least one fracture due to bone fragility (FF) [1-3], in other words a fracture resulting from minimal trauma or a fall that would not harm a healthy person. In women over age 50 , the annual FF incidence rate is $14 / 1000$, twice the incidence rate of cerebrovascular incidents and myocardial infarcts combined [4]. FFs cost Canada's healthcare services over $\$ 2$ billion annually [5,6], with costs expected to triple over the next 20 years $[7,8]$.

Recent statistics reveal that about two million Canadians suffered from osteoporosis defined by bone mineral density (BMD) [9], but BMD is an imperfect measure of bone strength. Although FFs are generally related to bone fragility related to osteoporosis [1,10-13], and the relative risk for FF increases with decreasing BMD, the majority of FFs occur in individuals without BMD-defined osteoporosis. The occurrence of a FF is a sentinel event predicting a future FF [14], at least doubling the risk of secondary fractures compared with age- and BMDmatched individuals without a FF $[15,16]$. Indeed, men and women with a hip or spine FF are at high risk for repeat fractures, irrespective of their BMD results, which may be normal. Of note, about half of hip fracture patients have sustained previous FFs $[17,18]$, suggesting that FFs are events that should guide preventive interventions. Hip fractures often precipitate decline in health or even death, and loss of mobility, with high associated costs for patients, families, society and the healthcare system [19-23].

The two mainstays of FF prevention are pharmaceutical interventions to strengthen bones, and fall prevention programs to maintain and improve strength and balance, including other strategies to reduce fall risk factors, keeping in mind that exercise also strengthens bones. The success of interventions to manage FFs more effectively, to identify and treat those with bone fragility, to maximize population health by preventing or delaying frailty, and to minimize costs [24-28] is mediated by the context of interventions within the local healthcare system $[29,30]$. Despite strong evidence of their effectiveness, prescription and adherence to osteoporosis treatment and fall prevention interventions following FFs remain sporadic and inconsistent in primary care. It is hoped that when post-fracture screening and fall prevention programs are systematically integrated, and secondary
FFs may be prevented in an additive or even synergistic manner [30,31].

In the context of current primary care reform, secondary fracture prevention program research must evaluate multidisciplinary and interorganizational strategies, with attention to the regional context of implementation, the providers, and the participants. The present paper includes the design and evaluation procedures for a novel secondary FF prevention program, involving collaboration between secondary healthcare practitioners (orthopedic surgeons and medical bone specialists), primary care physicians (PCPs), group practice nurses, and local and provincial fall prevention programs, being implemented in the province of Quebec, Canada. This work builds on the Osteoporosis and Peripheral fractures: Treatment and Investigation through Multidisciplinary care at the CHUS (OPTIMUS) intervention. The proposed intervention involves PCPs in the evaluation and treatment of osteoporosis following FFs treated by orthopedic surgeons [32-38] and integrates local and provincial fall prevention programs implemented in the province of Quebec, including the Personalized Multifactorial Intervention (PMI), an individualized program offered to the most frail elders considered at risk for falls [39]; and a community-based fall prevention program aimed primarily at improving balance and strength through exercise for elders who have fallen or are concerned with falls (Stand Up!) [40]. This integrated program will be orchestrated by site study coordinators.

The overarching aim is to investigate the effectiveness, cost-effectiveness and cost-utility of an integrated FF prevention program, and to obtain a portrait of the barriers and facilitating factors for such programs. More specifically, the objectives are:

1. to combine existing fall prevention and post-fracture management programs in the province of Quebec into integrated interdisciplinary FF prevention programs;

2. to compare the performance of these integrated programs to results from control sites, using a pragmatic study design;

3. to identify barriers as well as factors that improve effectiveness across different implementation regions;

4. and to develop and engage in active knowledge transfer activities in Quebec regions where integrated FF prevention programs are neither adequately nor successfully implemented. 


\section{Research questions and hypotheses Primary question}

Can an integrated FF program reduce the risk of a secondary FF in a population of patients 50 years of age and over, who sustained a FF 18 to 20 months previously?

\section{Secondary questions}

1) Can a post-FF management program be successfully integrated with PCPs' health care, and local and national fall prevention programs, from a patient and healthcare system perspective?

2) Is this integrated FF prevention program effective and cost-effective?

3) What are the barriers and factors that improve effectiveness across different implementation regions?

Drawing upon the literature on integrated healthcare, fall and fracture prevention, as well as the OPTIMUS study [32-38], we hypothesize that an integrated FF program can reduce the risk of a secondary fracture by at least $30 \%$ in the population of interest. In addition, by examining the implementation process of the program, we will make recommendations to circumvent the barriers to implementation, and to build upon the factors that lead to improved integration of the care providers involved in the program.

\section{Conceptual framework}

The research program will draw on the key principles of the Development Model for Integrated Care (DMIC) [41-43] to implement the proposed intervention, and the Model of Structuration of Interprofessional Collaboration (MSIC) to explore interorganizational collaboration and its links to the selected clinical outcomes [44].

The DMIC is a recent model for the development of an integrated program [41-43] that has been validated through a panel of Dutch experts and is currently implemented within three settings in The Netherlands. This project will tap into the first and second phases of the DMIC model: Initiative and design; and Experiment and execution. These serve as a checklist for the development of the program in each intervention region, and as a guideline during the focus group discussions with the participating healthcare professionals involved in the intervention.

The MSIC lists 10 indicators, grouped into four dimensions: Shared goals and vision; Internalization; Formalization; and Governance. These indicators capture facets of relationships between individuals engaged in a collaborative practice, and the organizational context in which they work [44]. The MSIC has been validated in various healthcare contexts, mostly in the province of Quebec
[45-47]. It will be used to guide the evaluation of collaboration among practitioners and organizations involved in the program (hospitals, orthopedists and medical bone specialists, PCPs in private practices, family medicine group (GMFs), and provincial and local fall prevention services).

\section{Methods}

\section{Study design}

A pragmatic, controlled trial design is being used to assess whether the intervention works in a setting that is as similar to routine practice as possible [48]. Within such a design, all participants are enrolled unless the study intervention might compromise patient safety; treating physicians and healthcare practitioners decide how the intervention is delivered; integrated models of healthcare are encouraged, as the intervention is delivered through the participation of a spectrum of practitioners in a range of healthcare organizations; and an intent-to-treat analysis is the only analysis possible [48-52].

\section{Setting}

The study is taking place in eleven hospitals and various fall prevention programs, located in eight different administrative regions of the province of Quebec. Of these, six hospitals are offering the integrated program in four different regions (Sherbrooke, Lanaudière, and Montréal), while participants recruited from the other five hospitals (in the Outaouais, Trois-Rivières, Longueuil, Côte-Nord, and Amos regions) will constitute the standard care control group. The choice of these hospitals and regions is based on the variety of fall prevention programs available in the geographic area surrounding the selected hospitals [53]. The broad variety of sites will maximize the external generalizability of the study results, and is intended to optimize the potential identification of barriers to and facilitating factors for implementation of an integrated FF prevention program.

\section{Ethical approval}

Given the large number of organizations involved, ethical aspects of this study were evaluated via a multi-center mechanism as recommended by the Ministère de la Santé et des Services Sociaux (MSSS). The Comité d'éthique de la recherche en santé chez l'humain du Centre hospitalier universitaire de Sherbrooke (CHUS) served as the principal ethics board and approved the final documents.

\section{Participants}

The study population consists of community-dwelling males and females, who are 50 years of age and over, who have a PCP (this is the case for $94 \%$ of this age group in Canada [54]), who are able to follow simple instructions, and who have sustained a FF within two months of the 
recruitment date. Participants presenting with the following conditions will be excluded: fracture at sites not commonly associated with osteoporosis such as toe, finger, hand, foot, patella, head, and cervical spine; severe kidney insufficiency (grade 4 or 5); or an advanced stage of cancer or any other disease from which the patient is likely to die within the next year.

\section{Recruitment}

Drawing upon the methodology of previous studies in a similar population [32-34,55], participants for intervention sites will be recruited by a study coordinator over a period of 12 months, and will provide their informed consent to participate and complete the baseline questionnaire. Three methods will be used to recruit intervention group participants:

1. Patients with FFs in participating outpatient orthopedic clinics will be identified by a study coordinator;

2. Hip fracture inpatients will be approached on the ward during their hospitalization;

3. And hospital emergency and ward discharge administrative data will be scanned for patients with a primary discharge code typical of a FF. These participants will be contacted by mail by the hospital to inform them about the research project and that a local study coordinator will contact them. Electronic discharge data allows patient identification within one week following discharge.

Due to budgetary and ethical considerations, only strategy 3 will be used to recruit participants in the control hospitals/regions. Should it be required as an alternative, FF patients' identification through the Régie de l'assurance maladie du Québec (RAMQ) database will be considered, as in the Recognizing Osteoporosis and its Consequences in Quebec (ROCQ) study [55]. The main limitations of this alternative strategy as well as strategy 3 are a delay required to obtain patients' information (estimated at two months in the case of the RAMQ data, one week for the hospital administrative data), and a potential selection bias (those more at risk for fractures, or who are younger and more educated may be more likely to consent); however, such strategies might be an efficient way to increase the external validity of the study by recruiting a broader range of fracture patients.

\section{Study interventions}

\section{Intervention group}

Nurses working in the Family Medicine Groups and Cliniques-Réseau (in Montreal) (GMF/CRs) located in the areas served by the recruiting hospitals will receive a workshop on evidence-based pharmacological interventions for osteoporosis, and benefits of exercise and fall prevention strategies to prevent FF. All PCPs within the intervention group regions will receive a pamphlet summarizing the workshop.

Upon recruitment, FF participants will be educated by the study coordinator about osteoporosis as the cause of their FF, the importance of a rapid screening evaluation for potentially treatable primary causes of bone fragility, the benefits of early and prolonged treatment, the options for treatment to be adapted for individuals, and will be asked permission to contact their PCP and community pharmacist. Participants' PCPs will receive written information containing a presumed osteoporosis diagnosis, investigations to be performed, correct interpretation of bone densitometry results in the context of a FF, treatment options adapted to the individual patient, and alternatives if the first prescriptions are not tolerated or are stopped.

The integrated intervention per se includes the following:

1. When possible, screening basic blood tests (e.g., calcium, phosphate, white blood cells, hemoglobin, platelets, vitamin D) in the context of a FF will be performed at the recruiting hospital laboratory, and the results will be transmitted to the participant's PCP with a personal letter explaining the importance of seeing the patient rapidly (ideally within one month), and the urgency of initiating an osteoporosis treatment. If the PCP is part of a GMF/CR [56], then the clinic nurse will receive a copy of the information sent to the PCP.

2. Following a region-specific a priori defined algorithm to identify the most relevant resource for the participant, the study coordinator or the GMF/CR nurse (when possible) will orient the participant to an appropriate fall prevention program, and organize his/her registration or placement on the waiting list. A local exercise and fall prevention program appropriate for the patient according to the participant's age, fracture risk, and abilities will be agreed upon by the study coordinator and the participant. The study coordinator will work with numerous local fall prevention champions supporting this research program, to establish and maintain an up-to-date list of available exercise and fall prevention programs at each site. The study coordinator will also encourage the participant to engage in additional physical activities at a comfortable level of intensity.

3. The participant will be called quarterly by the study coordinator or the GMF/CR nurse to monitor pharmacological treatment adherence, to detect and correct (if appropriate) inadequate intake or side effects affecting compliance, to answer questions, to encourage compliance, and to track fall and fracture information recorded in the participant diary. 
4. The study coordinator or the GMF/CR nurse will communicate with the participant's pharmacist at 6 and 12 months to confirm drug delivery to the participant (if the participant has been prescribed osteoporosis pharmacological treatment), and if possible to enlist this professional's help in encouraging treatment.

5. At each follow-up, if the patient is not taking an adequate pharmacological treatment, a letter will be sent again to the PCP (and the GMF/CR nurse, if appropriate) suggesting that they treat the patient according to the participant's 10-year fracture risk.

6. Participant adherence to the fall prevention program will be monitored at the mid-point and at the end of the program. If necessary, the study coordinator will arrange a program change to better fit the participant's needs.

\section{Control group}

The study coordinator will inform the participants about osteoporosis as the potential cause of their fracture. A lay pamphlet on strategies to prevent a secondary FF will be provided, including the recommendation to visit their PCPs and the need for fall prevention and pharmacological intervention in most patients.

\section{Outcomes and data collection}

All participants will be followed for a period of 18 months. A multilevel approach is being used, in which outcomes at the patient level will be measured with quantitative tools, and outcomes at the organization level (e.g., perception of the degree of integration and collaboration between organizations) will be measured simultaneously using qualitative techniques [57]. Combining both qualitative and quantitative measures will allow a better understanding and contextualisation of the quantitative results, and verification as to how organization level factors impact the effectiveness outcomes [57,58].

\section{Quantitative data}

With the exception of the first encounter with the participants recruited from the orthopedic clinics and the inpatients from the intervention sites with hip and other fractures, all data will be collected through phone surveys and the participant diary. A baseline questionnaire will be completed by all participants, including demographic data and relevant medical history (e.g., height, weight, smoking and drinking history, family history of hip fracture, use of glucocorticoids) and the CaMos questionnaire [59]. The Fracture Risk Assessment Tool (FRAX) score will be used, irrespective of BMD results availability [60]. A Canadian Association of Radiologists and Osteoporosis Canada 10-year absolute fracture risk (CAROC) score will be generated for participants who undergo a BMD test within $+/-3$ months of the sentinel event [59,61]. A study exit questionnaire will be administered at the end of the intervention or when the participant withdraws his/her consent to participate.

\section{Primary outcome}

The primary outcome is the incidence of secondary FF during the 18-month follow-up period, including the date of the event, related emergency room visit, and hospitalization. This will be ascertained during quarterly telephone surveys, and confirmed with the participant's hospital record when possible.

\section{Secondary outcomes}

Secondary outcomes will be assessed at 3, 6, 9, 12 and 18 months unless otherwise mentioned.

1. Initiation of osteoporosis treatment by the PCP (bisphosphonates or other effective osteoporosis drugs) [31], and compliance with osteoporosis treatment will be captured during telephone surveys. The data will be validated with the participant's pharmacist via the medication possession ratio, which is measured from the first to the last prescription, with the denominator being the duration from index to the exhaustion of the last prescription and the numerator being the days supplied over that period from first to last prescription and the numerator being the total number of days in the interval [62].

2. Time to first fall, and number of clinically significant falls will be reported by participants from their diary of fall events, during telephone followup. This prospective method has been found to be reliable, minimizing recall bias, in other fall prevention studies [63].

3. Fall-related hospitalizations will be recorded in the participant diary and at each telephone follow-up, and validated with the participant's hospital records.

4. FF-related death will be confirmed from the RAMQ administrative database.

5. Participants' quality of life will be documented biannually during telephone surveys, using the EQ5D-3 L questionnaire [64]. This is an extensively validated questionnaire that provides a global measure of the respondent's health status and quality of life [65-67].

6. Practice of physical activities will be measured using the Community Healthy Activities Model Program for Seniors (CHAMPS) [68,69]. This tool has demonstrated very good psychometric properties and sensitivity, even with low intensity physical activities. 
7. FF-related costs will be captured over the study duration. Medical costs from the participant's hospital record include: medical assessment, prescription and non-prescription drugs; and resource use related to the management of the FF and/or long-term complications, including hospitalization. Also, lost days of work, annual income (if the participant is in the labor force), travel to the hospital and/or rehabilitation facilities, parking, and out-of-pocket expenses for drugs and rehabilitation devices (e.g., splint) will be compiled. Protocol-driven costs will be excluded, with the exception of the costs related to the participant's fall prevention program.

8. Admission to a long-term care facility will be queried during each telephone survey.

9. All participants' perceptions of care integration will be captured in the exit questionnaire. In the absence of a formally validated instrument to measure the outcome of interest [70], the measurement tool will consist of a customized version of a questionnaire on the perception of care integration from a patient perspective [71]. Five questions, corresponding to the interaction subscale, are being used to investigate this study objective on program integration.

10. Intervention participant's satisfaction with the FF prevention program will be measured using questions similar to those used by Berendsen et al. for their assessment of the sources and amount of information preferred by the participant in the context of an integrated program [72], along with general questions with regards to the participant's satisfaction with the program.

11. Participants' expectations and whether they are perceived as met will be collected at the beginning and end of the program. The questionnaire is an adapted version of Gignac's Program Expectation Scale and uses a 3-point scale ranging from 1 (not at all likely) to 3 (extremely likely) [73]. Participants will also be asked to rate the extent to which they believe the program would produce (before the program) or has produced (end of the program) health benefits for themselves.

12. Individuals who chose to leave the program (or part of it) will be contacted by telephone to document the reason(s) for withdrawing while completing the exit questionnaire.

\section{Qualitative data}

Focus group sessions organized per intervention region will gather a purposeful sample of healthcare managers of fall prevention programs, medical bone specialists, orthopedic surgeons, PCPs and GMF nurses involved in the trial, as well as patients. The sessions are scheduled to last about 60 minutes in length. A maximum of eight professionals will participate per focus group, so sessions with healthcare professionals will be repeated twice for greater participation. The topics and questions of the semi-structured questionnaire will be guided by the conceptual frameworks selected for this project $[41,44]$. The first session (at baseline) will aim to understand both the factors for success and the potential barriers to the implementation of a FF prevention program. The second session will target the barriers and facilitating factors for maintenance of a FF prevention program, as well as measure the degree of integration between the organizations involved (at 12 months). The two focus groups for the patients (one at baseline and another one between 12 and 18 months post-recruitment) will be geared towards patients' expectations and satisfaction about the program, as well as perception of integration of care. All focus group sessions will be audiotaped and transcribed.

\section{Statistical analysis \\ Sample size}

Quantitative evaluation of entire cohort Based on preliminary (almost four years follow-up) results from the OPTIMUS project, the incidence of a secondary fracture at 16 months in the control group is expected to be $10 \%$; therefore, this incidence of fracture was used as a proxy for the sample size calculation of this project (primary outcome measured at 18 months). Considering the reported efficacy of antiresorptive drugs among others (average absolute reduction rate of 4\%) [74-77], the results obtained in the intervention group of the OPTIMUS cohort (expected absolute reduction rate in FF of 2.5\%), as well as the expected synergy with fall prevention programs, and collective orders that will allow for a rapid pharmacological intervention, an absolute reduction of $3 \%$ (i.e., a secondary fracture incidence at 18 months of $7 \%$ in the intervention group) is a conservative estimate of the effect to be detected. Under these assumptions and assuming a power of $80 \%$ and an alpha level of 5\%, 1,356 participants per group are necessary to verify the primary hypothesis. It is estimated that approximately $15 \%$ of the participants will be lost to follow-up or will withdraw from the study prior to the 18-month data collection time point. Therefore, a total of 1,596 participants will be recruited in each group (total $\mathrm{N}=3,192$ ).

Qualitative focus group analyses Based on the qualitative literature, it is estimated that 6 to 12 participants are required to achieve study themes redundancy $[78,79]$. Our targeted sample size should then allow for the saturation of the various barriers to and facilitators of the implementation of an integrated FF prevention program (first sessions' focus), as well as the qualitative 
assessment of the intensity of interorganizational collaboration within each intervention site (second sessions' focus) $[80,81]$.

\section{Data analysis \\ Quantitative component}

Descriptive summaries of baseline participant characteristics in the control and intervention groups will be generated. Any statistical differences (due to selection bias, for example) between the study groups or within a study group (between the different sites) will be tested using chi-square tests or Student's t-tests (or their nonparametric equivalents if necessary) and accounted for in the following analyses. According to the pragmatic design standards, statistical analysis of the data will follow the intention-to-treat principle; i.e., the analysis will include all patients regardless of their compliance with their study group intervention. The implementation process will also be documented with descriptive statistics.

\section{Primary outcome}

The numbers of participants presenting with a least one secondary FF at 18 months will be compared using a chi-square test. A logistic regression model will be fit to assess the intervention effect, while adjusting for variables thought to influence the outcome and accommodating any imbalance between groups at baseline. The intervention effect and its 95\% confidence interval will be generated. Descriptive statistics on the cumulative incidence of recurrent FF will also be generated for each group.

\section{Secondary outcomes}

Initiation and compliance with pharmacological osteoporosis treatment at 3, 6, 9, 12 and 18 months, and mortality rate will be analysed independently, as for the primary outcome. Time to first fall will be compared between study groups using a time-to-event type of analysis (log-rank test or Gehan-Wilcoxon, depending on the data distribution). A Cox regression model that allows for the adjustment of baseline variables that have been shown to influence the outcome will be used. The difference in the number of significant falls and fallrelated hospitalizations will be assessed using a Poisson regression model. Participants' quality of life and practice of physical activities measured over time will be fit and compared between the two study groups using an analysis of variance (ANOVA) for repeated measures. The total score of the participant's perception of care integration will be generated for each participant by summing up all questionnaire items. Group scores will be compared using a linear regression model. If numbers allow, a sub-group analysis will be considered among the intervention group to test the effect of provincial versus local fall prevention programs as a covariate on the primary outcome.

The cost-effectiveness ratio will be expressed as the difference in costs between the study groups, divided by the difference in secondary fracture rates between the two groups. Costs will be calculated as the units of resources used in the treatment of a FF, multiplied by the cost of one unit. The uncertainty concerning the incremental cost, the incremental effectiveness, and the incremental cost-effectiveness ratio will be estimated by conducting probabilistic analysis through non-parametric bootstrapping [82]. Results from the bootstrapping exercise will be depicted by cost-effectiveness acceptability curves. All quantitative analyses will be performed with the SPSS 18 software (SPSS, Inc., 2009, Chicago, IL), with the exception of the economic analyses, which will be performed using Oracle Crystal Ball (http://www.oracle.com/ us/products/applications/crystalball/index.html).

\section{Qualitative component}

Focus group audio tapes and transcripts will be reviewed simultaneously to assess validity of the transcription process. An interpretive approach will inform the analysis of the transcript $[83,84]$. Two examiners will read the transcripts independently, and a thematic analysis will be conducted to identify themes that emerge, that correspond to the study questions. Codes will be compared and discussed until an acceptable inter-judge reliability is obtained [83]. Data analysis will be conducted using the scoring scheme proposed by D'Amour and colleagues [44,85], and supported by the NVivo software. An audit trail will be compiled to record the steps taken and decisions made during the analytical process, which will ensure the reproducibility of the analysis. Data saturation will be considered to have been reached when a theme has been discussed by at least six interviewees [78]. Analysis will examine coherence and differences among the focus group participants, and will be discussed within a small subgroup of the research team. Integration with the quantitative data will be considered, especially for explanation of any foreseen variation in the primary outcome between the intervention sites.

\section{Knowledge translation and dissemination}

Several activities will serve to meet the fourth objective of this project related to knowledge translation throughout the intervention [86]:

1. A panel of volunteer healthcare professionals involved in the treatment of FF and public health, as well as a patient representative from the intervention regions, will design the pamphlets for the control participants, and for the intervention PCPs. Webminars will also be offered to healthcare 
professionals in the intervention regions. This will be done through a modified Delphi survey [87-89] with refinement using a focus group including a maximum of 12 participants. This initiative will create expectations among the professionals and their communities, while sensitizing them to the clinical and economic burden of FFs. This strategy will also empower these professionals vis-à-vis the research team, thus creating a fertile environment for active collaboration and knowledge transfer during the trial.

2. The personalized letter sent to the intervention group participants' PCPs is an excellent opportunity for knowledge transfer and continued education. When carefully designed, this mode of communication between secondary and primary care has shown benefits, especially with the older adult population [90-92].

3. A final report as well as an information session will be prepared for the MSSS and the Institut national de santé publique du Québec (INSPQ) decision makers and managers to inform them about the study results and to promote the sustainability and expanded geographical coverage of the program.

4. We anticipate that the process of evaluation of the currently available fall prevention programs will affect the willingness of managers to pursue evaluation of the organization (e.g., hospitals, medical group practices, provincial and local fall prevention programs) and delivery processes of their programs. Such a bottom-up approach might eventually improve the knowledge translation and dissemination of the proposed study recommendations with the confidence that these will have a longer and measurable impact upon the organizations involved. Moreover, the involvement of collaborators committed throughout major networks of action among the government and osteoporosis knowledge transfer groups should facilitate the translation of the results among the population and stimulate the creation of other similar initiatives in the province.

5. Conventional knowledge translation strategies such as presentations to national and international conferences and publications in peer-reviewed openaccess journals will also be undertaken.

\section{Discussion}

This trial is testing a comprehensive, integrated secondary FF prevention program in a real-life setting, and is designed to optimize translation of research evidence into practice [93-95]. The pragmatic evaluative design of this project, rooted in the Canadian Institutes of Health Research Integrated Knowledge Translation process [96], will provide estimates of the effectiveness of a FF prevention program in different socioeconomic contexts, thereby increasing the generalizability of the results.

FF prevention is needed for much longer time periods than the length of this study, and the creation of a cohort of patients who have experienced FFs offers an opportunity to further address continuity and gaps regarding integrated FF prevention programs. The study team is seeking funding for continuing research, including follow-up at five years.

A limitation of this study lies in the recruitment strategies. Patients in the control group, identified through administrative databases, may present with more severe risk factors, which translate into a higher likelihood of a secondary FF. This may create a selection bias between the recruiting sites, which will be accounted for in the statistical analyses. In the intervention group, a surveillance bias for secondary FF is possible, since this group is sensitized to FFs. This may reduce the observed study effect; however, the large size of this trial, based on conservative effect estimates, should provide sufficient power to detect the intervention effect, if present. Finally, control sites/regions will be monitored throughout the trial to identify emerging fall prevention programs. This will be accounted for in the statistical analysis should participants take part in these programs. Another limitation related to the external validity of this study lies in the organizational variations between participating regions. However, the qualitative component of the study should shed light on those variations and help in a more accurate interpretation of the results.

The number of aging baby boomers, increasing longevity, and higher standards for quality of care are combining to create the 'perfect storm' of healthcare issues that will emerge over the coming decades. Rapidly increasing numbers of FFs are a significant concern for older adults, and place enormous demands on already stretched health resources. Solutions to slow this 'epidemic' have already been developed and tested in practice: falls can be prevented through existing programs; cost-effective drugs decrease the risk for fractures in highrisk groups; and care following FFs is improving. Nevertheless, the impact of these interventions is blunted by low patient participation and poor intervention integration.

This novel integrated FF prevention program aims to improve interorganizational collaboration and communication between both primary and secondary healthcare practitioners. As we help health professionals to improve the continuum of care and patient-centered care, the goal is also to improve chronic disease prevention and management.

\section{Abbreviations}

BMD: Bone mineral density; CHUS: Centre hospitalier universitaire de Sherbrooke; CR: Clinique-réseau; DMIC: Development Model for Integrated Care; FF: Fragility fracture; GMF: Family medicine group; INSPQ: Institut national de santé publique du Québec; MSIC: Model of structuration of 
interprofessional collaboration; MSSS: Ministère de la santé et des services sociaux; OPTIMUS: Treatment and investigation through multidisciplinary care at the CHUS; PCP: Primary care physician; PMI: Personalized multifactorial intervention; RAMQ: Régie de l'assurance maladie du Québec; ROCQ: Recognize osteoporosis and its consequences in Quebec.

\section{Competing interests}

The authors declare that they have no competing interests.

\section{Authors' contributions}

All authors participated in the conception and design of the study. IG drafted the manuscript. All authors read and approved the final manuscript. The funding body has not been involved in design, in the collection, analysis, and interpretation of data; in the writing of the manuscript; and in the decision to submit the manuscript for publication. All authors read and approved the final manuscript.

\section{Acknowledgements}

The authors acknowledge the assistance of Meg Sears for grammatical revision of the manuscript

\section{Author details}

'Department of Family Medicine and Emergency Medicine, University of Sherbrooke, Sherbrooke, QC, Canada. ${ }^{2}$ Centre de recherche clinique ÉtienneLe Bel, Sherbrooke, QC, Canada. ${ }^{3}$ School of Rehabilitation, University of Sherbrooke, Sherbrooke, QC, Canada. ${ }^{4}$ Centre de recherche sur le vieillissement, Sherbrooke, QC, Canada. ${ }^{5}$ Department of Medicine, University of Sherbrooke, Sherbrooke, QC, Canada. ${ }^{6}$ Institut national d'excellence en santé et en services sociaux, Montreal, QC, Canada. ${ }^{7}$ Health and Social Services Center- University Institute of Geriatric of Sherbrooke, Sherbrooke, QC, Canada. ${ }^{8}$ Keenan Research Centre, Toronto, ON, Canada. ${ }^{9}$ St Michael's Hospital, Department of Surgery, University of Toronto, Toronto, ON, Canada. ${ }^{10}$ Ministère de la Santé et des Services sociaux du Québec, Québec, QC, Canada. ${ }^{11}$ School of Rehabilitation, University of Montreal, Montreal, QC, Canada. ${ }^{12}$ Centre de recherche de I'Institut universitaire de gériatrie de Montreal, Montreal, QC, Canada. ${ }^{13}$ Centre for Research and Expertise in Social Gerontology (CRESG), CSSS Cavendish-Centre affilié universitaire, Montreal, QC, Canada. ${ }^{14}$ Institut de recherche en santé publique de I'Université de Montréal (IRSPUM), Montreal, QC, Canada. ${ }^{15}$ Institut national de santé publique du Quebec, Québec, QC, Canada. ${ }^{16}$ Department of Health Community Sciences, University of Sherbrooke, Longueuil, QC, Canada. ${ }^{17}$ Osteoporosis Canada, Toronto, ON, Canada. ${ }^{18}$ University of Lausanne, Lausanne, Switzerland.

Received: 10 December 2012 Accepted: 16 January 2013 Published: 24 January 2013

\section{References}

1. Kanis JA, Oden A, Johnell O, Jonsson B, de Laet C, Dawson A: The burden of osteoporotic fractures: a method for setting intervention thresholds. Osteoporos Int 2001, 12(5):417-427.

2. van Staa TP, Dennison EM, Leufkens HG, Cooper C: Epidemiology of fractures in England and Wales. Bone 2001, 29(6):517-522.

3. International Osteoporosis Foundation: Osteoporosis: Facts and statistics; www.iofbonehealth.org/facts-and-statistics.

4. Cummings SR, Melton L: Epidemiology and outcomes of osteoporotic fractures. Lancet 2002, 359(9319):1761-1767.

5. Leslie WD, O'Donnell S, Lagace C, Walsh P, Bancej C, Jean S, Siminoski K, Kaiser S, Kendler DL, Jaglal S, Osteoporosis Surveillance Expert Working Group: Population-based Canadian hip fracture rates with international comparisons. Osteoporos Int 2010, 21(8):1317-1322.

6. Bliuc D, Nguyen ND, Milch VE, Nguyen TV, Eisman JA, Center JR: Mortality risk associated with low-trauma osteoporotic fracture and subsequent fracture in men and women. JAMA 2009, 301(5):513-521.

7. Scott V, Wagar L, Elliott S: Falls \& Related Injuries among Older Canadians: Fall-related hospitalization \& intervention initiatives. Victoria; 2010.

8. SMARTRISK: The economic burden of injury in Canada. Toronto; 2009 .

9. Osteoporosis Canada: Osteoporosis at-a-glance; http://www.osteoporosis.ca/ index.php/ci_id/5526/la_id/1.htm.
10. Jones G, Nguyen T, Sambrook PN, Kelly PJ, Gilbert C, Eisman JA: Symptomatic fracture incidence in elderly men and women: the Dubbo Osteoporosis Epidemiology Study (DOES). Osteoporos Int 1994, 4(5):277-282.

11. Meisinger C, Wildner M, Stieber J, Heier M, Sangha O, Doring A Epidemiology of limb fractures. Orthopäde 2002, 31(1):92-99.

12. Johnell O, Kanis J: Epidemiology of osteoporotic fractures. Osteoporos Int 2005, 16(Suppl 2):S3-S7.

13. Anonymous: NIH Consensus Development Panel on Osteoporosis Prevention, Diagnosis, and Therapy, March 7-29, 2000: highlights of the conference. South Med J 2001, 94(6):569-573.

14. Wustrack R, Seeman E, Bucci-Rechtweg C, Burch S, Palermo L, Black DM: Predictors of new and severe vertebral fractures: results from the HORIZON Pivotal Fracture Trial. Osteoporos Int 2012, 23(1):53-58.

15. Bliuc D, Ong CR, Eisman JA, Center JR: Barriers to effective management of osteoporosis in moderate and minimal trauma fractures: a prospective study. Osteoporosis Int 2005, 16(8):977-982.

16. Kanis JA, Johnell O, De Laet $C$, Johansson $\mathrm{H}$, Oden A, Delmas $P$, Eisman J, Fujiwara S, Garnero P, Kroger H, McCloskey EV, Mellstrom D, Melton L, Pols $H$, Reeve J, Silman A, Tenenhouse A: A meta-analysis of previous fracture and subsequent fracture risk. Bone 2004, 35(2):375-382.

17. Robbins J, Aragaki AK, Kooperberg C, Watts N, Wactawski-Wende J, Jackson RD, LeBoff MS, Lewis CE, Chen Z, Stefanick ML, Cauley J: Factors associated with 5-year risk of hip fracture in postmenopausal women. JAMA 2007, 298(20):2389-2398.

18. Netelenbos JC, Lems WF, Geusens PP, Verhaar HJ, Boermans AJ, Boomsma MM, Mulder PG, Papapoulos SE: Spine radiographs to improve the identification of women at high risk for fractures. Osteoporos Int 2009, 20(8):1347-1352

19. Wiktorowicz ME, Goeree R, Papaioannou A, Adachi JD, Papadimitropoulos E: Economic implications of hip fracture: health service use, institutional care and cost in Canada. Osteoporos Int 2001, 12(4):271-278.

20. Braithwaite RS, Col NF, Wong JB: Estimating hip fracture morbidity, mortality and costs. J Am Geriatr Soc 2003, 51(3):364-370.

21. Office of Technology Assessment, US Congress: Hip Fracture Outcomes in People Age 50 and Over-Background Paper. Washington, DC: OTA-BP-H-120; 1994.

22. US Department of Health and Human Services: Bone Health and Osteoporosis: A Report of the Surgeon General. Rockville, MD: 2004.

23. Cauley JA, Thompson DE, Ensrud KC, Scott JC, Black D: Risk of mortality following clinical fractures. Osteoporos Int 2000, 11(7):556-561.

24. Oliver D: Development of services for older patients with falls and fractures in England: successes, failures, lessons and controversies. Arch Gerontol Geriatr 2009, 49(Suppl 2):S7-S12.

25. Elliot-Gibson V, Bogoch ER, Jamal SA, Beaton DE: Practice patterns in the diagnosis and treatment of osteoporosis after a fragility fracture: a systematic review. Osteoporos Int 2004, 15(10):767-778.

26. Bogoch ER, Elliot-Gibson V, Beaton DE, Jamal SA, Josse RG, Murray TM: Effective initiation of osteoporosis diagnosis and treatment for patients with a fragility fracture in an orthopaedic environment. J Bone Joint Surg Am 2006, 88(1):25-34.

27. Sander B, Elliot-Gibson V, Beaton DE, Bogoch ER, Maetzel A: A coordinator program in post-fracture osteoporosis management improves outcomes and saves costs. J Bone Joint Surg Am 2008, 90(6):1197-1205.

28. Eisman JA, Bogoch ER, Dell R, Harrington JT, McKinney RE Jr, McLellan A, Mitchell PJ, Silverman S, Singleton R, Siris E, for the ASBMR Task Force on Secondary Fracture Prevention: Making the first fracture the last fracture: ASBMR task force report on secondary fracture prevention. J Bone Miner Res 2012, 27(10):2039-2046.

29. Gillespie LD, Gillespie WJ, Robertson MC, Lamb SE, Cumming RG, Rowe BH: WITHDRAWN: Interventions for preventing falls in elderly people. Cochrane Database Syst Rev 2009, 2(2):CD000340.

30. Barrack CM, McGirr EE, Fuller JD, Foster NM, Ewald DP: Secondary prevention of osteoporosis post minimal trauma fracture in an Australian regional and rural population. Aust I Rural Health 2009, 17(6):310-315.

31. Papaioannou A, Morin S, Cheung AM, Atkinson S, Brown JP, Feldman S, Hanley DA, Hodsman A, Jamal SA, Kaiser SM, Kvern B, Siminoski K, Leslie WD, Scientific Advisory Council of Osteoporosis Canada: 2010 clinical practice guidelines for the diagnosis and management of osteoporosis in Canada: summary. CMAJ 2010 2010, 182(17):1864-1873.

32. Cabana F, Lambert D, Beaulieu M, Boire G: Priming primary care practitioners to treat osteoporosis in their patients with a fragility fracture. J Rheumatol 2010, 37(6):1313. 
33. Boire G, Beaulieu M, Lambert D, Cabana F: The OPTIMUS intervention: primary care practitioners treating osteoporosis in up to $64 \%$ of patients with fragility fracture. J Bone Miner Res 2009, 24(Suppl 1).

34. Boire G, Cabana F, Beaulieu M, Lambert D, Robindaine J, Poirier N, Larivee L, et al: How frequent are primary conditions affecting options for osteoporosis treatment among fracture patients seen by orthopaedic surgeons? Ann Rheum Dis 2008, 67(suppl. 2):298.

35. Boire G, Cabana F, Beaulieu M, Lambert D, Robindaine J, Poirier N, Larivee L: Primary conditions potentially affecting treatment of osteoporosis in fracture patients. J Rheumatol 2008, 37(6):1271-1354.

36. Beaulieu MC, Gosselin S, Gaboury I, Vanasse A, Cabana F, Boire G: Treating osteoporosis after a fragility fracture: the family physician as the Hub. J Bone Joint Surg Br 2012, 94-B:196. no. SUPP XXXVIII.

37. Cabana F, Beaulieu M, Lambert D, Côté PY, Vaillancourt M, Beaulieu MC, Roux S, Boire G: Incidence of subsequent fractures according to age and site of initial non- vertebral fractures: the first 3 years of the OPTIMUS initiative. J Bone Miner Res 2011, 36(Suppl. 1).

38. Boire G, Cabana F, Mikhail S, Lambert D: Who is Not treated following the implementation of OPTIMUS, a successful initiative to treat osteoporosis following a fragility fracture. J Bone Miner Res 2011, 26(Suppl 1).

39. Institut national de santé publique du Québec: Personalized Multifactorial Intervention; www.inspq.qc.ca/dossiers/imp/documents/pied_pmi.pdf.

40. Institut national de santé publique du Québec: Falls prevention among seniors living at home; www.inspq.qc.ca/dossiers/imp/documents/ pied_stand up.pdf.

41. Minkman MM, Ahaus KT, Huijsman R: A four phase development model for integrated care services in the Netherlands. BMC Health Serv Res 2009, 9:42.

42. Minkman M, Ahaus K, Fabbricotti I, Nabitz U, Huijsman R: A quality management model for integrated care: results of a Delphi and concept mapping study. Int J Qual Health Care 2009, 21(1464-3677; 1):66-75.

43. Minkman MM, Vermeulen RP, Ahaus KT, Huijsman R: The implementation of integrated care: the empirical validation of the development model for integrated care. BMC Health Serv Res 2011, 11(1):177.

44. D'Amour D, Goulet L, Labadie JF, Martin-Rodriguez LS, Pineault R: A model and typology of collaboration between professionals in healthcare organizations. BMC Health Serv Res 2008, 8:188.

45. Beaulieu MD, Denis JL, D'Amour D, Gaudreau J, Haggerty J, Hudon E, Jobin G, Lamothe L, Gilbert F, Guay H, Cyr G, Lebeau R: Limplantation des Groupes de médecine de famille: le défi de la réorganisation de la pratique et de la collaboration interprofessionnelle, Étude de cas dans cinq GMF da la première vague au Québec. Montréal; 2006.

46. D'Amour D, Goulet L, Pineault R, Labadie JR, Remondin M: Comparative study of interorganizational collaboration in four health regions and its effects: the case of perinatal services. R04-07 Montréal; 2004.

47. D'Amour D, Sicotte C, Lévy R: Un modèle de structuration de l'action collective dans les services de santé de première lignes au Québec. Sciences Sociales et Santé 1999, 17(3):67-94.

48. Bratton DJ, Nunn AJ: Alternative approaches to tuberculosis treatment evaluation: the role of pragmatic trials. Int J Tuberc Lung Dis 2011, 15(4):440-446.

49. Treweek S, Zwarenstein M: Making trials matter: pragmatic and explanatory trials and the problem of applicability. Trials 2009, 10:37.

50. Tunis SR, Stryer DB, Clancy CM: Practical clinical trials: increasing the value of clinical research for decision making in clinical and health policy. JAMA 2003, 290(12):1624-1632.

51. Riddle DL, Johnson RE, Jensen MP, Keefe FJ, Kroenke K, Bair MJ, Ang DC: The pragmatic-explanatory continuum indicator summary (PRECIS) instrument was useful for refining a randomized trial design: experiences from an investigative team. J Clin Epidemio/ 2010, 63(11):1271-1275.

52. Roland M, Torgerson DJ: What are pragmatic trials? BMJ 1998, 316(7127):285.

53. Champagne F, Gagnon I, Baldé T: Évaluation de l'implantation du continuum de services en prevention des chutes chez les aînés vivant à domicile; http:// www.fecst.gouv.qc.ca/fileadmin/documents/R09-02.pdf.

54. Statistics Canada: Calculations by HRSDC based on Statistics Canada. Regular medical doctor, by age group and sex, household population aged 12 and over, Canada, provinces, territories, health regions (June 2005 boundaries) and peer groups, every 2 years (CANSIM Table 105-0458). Ottawa; 2006.

55. Bessette L, Ste-Marie L, Jean S, Shawn Davison K, Beaulieu M, Baranci M, Bessant J, Brown JP: Recognizing osteoporosis and its consequences in Quebec (ROCQ): Background, rationale, and methods of an anti- fracture patient health-management programme. Contemp Clin Trials 2008, 29(2):194-210.

56. Gouvernement du Québec: Medical clinics; www.santemontreal.qc.ca/en/ where-to-go/medical-clinics/\#c1944.

57. Tashakkori A, Teddlie C: Mixed methodology: combining qualitative and quantitative approaches. Thousand Oaks, California: Sage; 1998.

58. Creswell JW: Qualitative Inquiry and Research Design: Choosing among five traditions. Thousand Oaks: Sage Publications; 1998.

59. Leslie WD, Berger C, Langsetmo L, Lix LM, Adachi JD, Hanley DA, loannidis G, Josse RG, Kovacs CS, Towheed T, Kaiser S, Olszynski WP, Prior JC, Jamal S, Kreiger N, Goltzman D, Canadian Multicentre Osteoporosis Study Research Group: Construction and validation of a simplified fracture risk assessment tool for Canadian women and men: results from the CaMos and Manitoba cohorts. Osteoporos Int 2011, 22(6):1873-1883.

60. Watts NB: The fracture risk assessment tool (FRAX(R)): applications in clinical practice. J Womens Health (Larchmt) 2011, 20(4):525-531.

61. Leslie WD, Lix LM, Manitoba Bone Density Program: Simplified 10-year absolute fracture risk assessment: a comparison of men and women. J Clin Densitom 2010, 13(2):141-146.

62. Scott Leslie R: Calculating Medication Compliance, Adherence, and Persistence in Administrative Pharmacy Claims Databases; www.wuss.org/proceedings08/ 08WUSS\%20Proceedings/papers/anl/anl09.pdf.

63. Ganz DA, Higashi T, Rubenstein LZ: Monitoring falls in cohort studies of community-dwelling older people: effect of the recall interval. $J$ Am Geriatr Soc 2005, 53(12):2190-2194.

64. Rabin R, de Charro F: EQ-5D: a measure of health status from the EuroQol Group. Ann Med 2001, 33(5):337-343.

65. Ware J Jr, Kosinski M, Keller SD: A 12-Item Short-Form Health Survey: construction of scales and preliminary tests of reliability and validity. Med Care 1996, 34(3):220-233.

66. Jakobsson U, Westergren A, Lindskov S, Hagell P: Construct validity of the SF-12 in three different samples. J Eval Clin Pract 2011, 18(3):560-566.

67. Jakobsson U: Using the 12-item Short Form health survey (SF-12) to measure quality of life among older people. Aging Clin Exp Res 2007, 19(6):457-464.

68. Stewart AL, Mills KM, King AC, Haskell WL, Gillis D, Ritter PL: CHAMPS physical activity questionnaire for older adults: outcomes for interventions. Med Sci Sports Exerc 2001, 33(7):1126-1141.

69. Harada ND, Chiu V, King AC, Stewart AL: An evaluation of three self-report physical activity instruments for older adults. Med Sci Sports Exerc 2001, 33(6):962-970

70. Strandberg-Larsen $M$, Krasnik A: Measurement of integrated healthcare delivery: a systematic review of methods and future research directions. Int J Integr Care 2009, 9:e01.

71. Farup PG, Blix I, Forre S, Johnsen G, Lange O, Johannessen R, Petersen $H$ : What causes treatment failure - the patient, primary care, secondary care or inadequate interaction in the health services? BMC Health Serv Res 2011, 11:111.

72. Berendsen AJ, de Jong GM, Schuling J, Bosveld HE, de Waal MW, Mitchell GK, van der Meer K, Meyboom-de Jong B: Patient's need for choice and information across the interface between primary and secondary care: a survey. Patient Educ Couns 2010, 79(1):100-105.

73. Gignac MA: An evaluation of a psychotherapeutic group intervention for persons having difficulty coping with musculoskeletal disorders. Soc Work Health Care 2000, 32(1):57-75.

74. Harrington JT, Ste-Marie LG, Brandi ML, Civitelli R, Fardellone P, Grauer A, Barton I, Boonen S: Risedronate rapidly reduces the risk for nonvertebral fractures in women with postmenopausal osteoporosis. Calcif Tissue Int 2004, 74(2):129-135

75. Wells G, Cranney A, Peterson J, Boucher M, Shea B, Robinson V, Coyle D, Tugwell P: Risedronate for the primary and secondary prevention of osteoporotic fractures in postmenopausal women. Cochrane Database Syst Rev 2008, 1(1):CD004523

76. Wells GA, Cranney A, Peterson J, Boucher M, Shea B, Robinson V, Coyle D, Tugwell $P$ : Alendronate for the primary and secondary prevention of osteoporotic fractures in postmenopausal women. Cochrane Database Syst Rev 2008, 1(1):CD001155.

77. Langsetmo LA, Morin S, Richards JB, Davison KS, Olszynski WP, Prior JC, Josse R, Goltzman D, CaMos Research Group: Effectiveness of antiresorptives for the prevention of nonvertebral low-trauma fractures in a populationbased cohort of women. Osteoporos Int 2009, 20(2):283-290. 
78. Guest $G$, Bunce A, Johnson L: How many interviews Are enough? an experiment with data saturation and variability. Field methods 2006, 18(1):59-82

79. Morse JM: Determining sample size. Qual Health Res 2000, 10(1):3-5.

80. Stewart DW, Shamdasani PN, Rook DW: Focus groups: theory and practice. 2nd edition. Thousand Oaks, California: SAGE Publications; 2007.

81. Fern EF: The Use of focus groups for idea generation: the effects of group size, acquaintanceship, and moderator on response quantity and quality. J Mark Res 1982, 19(1):1-13.

82. Claxton K: The irrelevance of inference: a decision-making approach to the stochastic evaluation of health care technologies. J Health Econ 1999, 18(3):341-364.

83. Miles MB, Huberman AM: Qualitative data analysis: an expanded sourcebook. 2nd edition. Thousand Oaks, California: Sage; 1994.

84. Thorne S, Kirkham SR, MacDonald-Emes J: Interpretive description: a noncategorical qualitative alternative for developing nursing knowledge. Res Nurs Health 1997, 20(2):169-177.

85. Hsieh HF, Shannon SE: Three approaches to qualitative content analysis. Qual Health Res 2005, 15(1049-7323; 9):1277-1288.

86. Sudsawad P: A conceptual framework to increase usability of outcome research for evidence-based practice. Am J Occup Ther 2005, 59(3):351-355.

87. Holey EA, Feeley JL, Dixon J, Whittaker VJ: An exploration of the use of simple statistics to measure consensus and stability in Delphi studies. BMC Med Res Methodol 2007, 7(1471-2288):52.

88. de Villiers MR, de Villiers PJ, Kent AP: The Delphi technique in health sciences education research. Med Teach 2005, 27(0142-159; 7):639-643.

89. Hasson F, Keeney S, McKenna H: Research guidelines for the Delphi survey technique. J Adv Nurs 2000, 32(0309-2402; 4):1008-1015.

90. Garasen $\mathrm{H}$, Johnsen R: The quality of communication about older patients between hospital physicians and general practitioners: a panel study assessment. BMC Health Serv Res 2007, 7:133.

91. Berendsen AJ, de Jong GM, Meyboom-de Jong B, Dekker JH, Schuling J: Transition of care: experiences and preferences of patients across the primary/secondary interface - a qualitative study. BMC Health Serv Res 2009, 9:62.

92. Jaglal SB, Hawker G, Bansod V, Salbach NM, Zwarenstein M, Carroll J, Brooks D, Cameron C, Bogoch E, Jaakkimainen L, Kreder H: A demonstration project of a multi-component educational intervention to improve integrated post-fracture osteoporosis care in five rural communities in Ontario, Canada. Osteoporos Int 2009, 20(2):265-274.

93. Geusens P, Dinant $\mathrm{G}$ : Integrating a gender dimension into osteoporosis and fracture risk research. Gend Med 2007, 4(Suppl B):S147-S161.

94. Gates S, Fisher JD, Cooke MW, Carter YH, Lamb SE: Multifactorial assessment and targeted intervention for preventing falls and injuries among older people in community and emergency care settings: systematic review and meta-analysis. BMJ 2008, 336(7636):130-133.

95. Glasgow RE, Lichtenstein E, Marcus AC: Why don't we see more translation of health promotion research to practice? Rethinking the efficacy-toeffectiveness transition. Am J Public Health 2003, 93(8):1261-1267.

96. Canadian Institutes for Health Research: More About Knowledge Translation at CIHR. www.cihr-irsc.gc.ca/e/39033.html.

doi:10.1186/1748-5908-8-10

Cite this article as: Gaboury et al:: Partnership for fragility bone fracture care provision and prevention program (P4Bones): study protocol for a secondary fracture prevention pragmatic controlled trial. Implementation Science 2013 8:10.

\section{Submit your next manuscript to BioMed Central and take full advantage of:}

- Convenient online submission

- Thorough peer review

- No space constraints or color figure charges

- Immediate publication on acceptance

- Inclusion in PubMed, CAS, Scopus and Google Scholar

- Research which is freely available for redistribution 